\title{
Glycerol as a Selective Agent for Auxotrophs of Verticillium dahliae
}

\author{
By J. E. PUHALLA \\ Agricultural Research Service, U.S. Department of Agriculture, National Cotton \\ Pathology Research Laboratory, College Station, Texas 77840, U.S.A.
}

(Received I2 August I975; revised 20 January 1976)

\section{INTRODUCTION}

Although conidia of Verticillium dahliae germinate and grow on a liquid minimal medium containing glycerol (Isaac, 1949; Vega \& Le Tourneau, 1971), most of them die on the same medium solidified with agar. Because only actively growing conidia are killed, a medium was devised that selects auxotrophic variants in populations of prototrophic conidia.

\section{METHODS}

Organisms. Wild-type isolate T9 of Verticillium dahliae Kleb. was recovered from diseased cotton in California, U.S.A. Strains met-I (requires methionine), nic-25 (requires nicotinamide) and nic- $I$ ade- $I O$ (requires nicotinamide and adenine) were recovered from T 9 conidia irradiated with ultraviolet light (Puhalla \& Mayfield, 1974). Additional studies were made on two other wild isolates of $V$. dahliae, $\mathrm{v} 44$ from the U.S.A. and is from the United Kingdom, and on an isolate of $V$. albo-atrum from southern Australia.

Conidia were harvested from 5- to Io-day-old colonies on PCDA agar medium (Puhalla, 1973) at $24^{\circ} \mathrm{C}$. Care was taken to sample only conidia from the periphery of the colony where the black microsclerotia were not yet visible. Unless otherwise stated, conidial spreads were incubated at $24{ }^{\circ} \mathrm{C}$.

Media. Minimal medium consisted of a salts solution (Puhalla \& Mayfield, 1974) plus a carbon source added before autoclaving. In one test, Czapek-Dox salt solution (Heale, 1966) was substituted for the minimal salts. Minimal medium was solidified with the following agars: Bacto agar from Difco; BBL agar from Becton, Dickinson and Co., Cockeysville, Maryland, U.S.A.; laboratory grade agar from Fisher Scientific Co., Fair Lawn, New Jersey, U.S.A.; and Ionagar no. 2 from Oxoid. The minimal medium was also solidified with silica gel after the method of Funk \& Krulwich (1964): sterile, double-strength minimal medium $(20 \mathrm{ml})$ was added at room temperature to sterile $7 \%(\mathrm{w} / \mathrm{v})$ aqueous $\mathrm{KOH}$ solution $(20 \mathrm{ml})$ containing $10 \%$ (w/v) silica gel (Grade 923, 100 to 200 mesh, Fisher Scientific Co.). Aqueous orthophosphoric acid $(17 \%, \mathrm{v} / \mathrm{v} ; 4 \mathrm{ml})$ was then added, and the mixture immediately poured into two Petri dishes.

Minimal agar medium was treated with activated charcoal by autoclaving minimal salts solution containing $2 \%(w / v)$ agar and I \% (w/v) charcoal (Darco G-60, Fisher Scientific Co.) and filtering the hot mixture through Whatman No. I paper to remove the charcoal. The filtrate was amended with a carbon source and re-autoclaved.

Overlay medium $(\mathrm{CN})$ contained $(\%, w / v)$ : malt extract, 0.5 ; yeast extract, 0.5 ; peptone 0.5 ; and agar, $0.75 . \mathrm{CN}(5 \mathrm{ml})$, cooled to $50{ }^{\circ} \mathrm{C}$, was poured over each plate of medium containing glycerol. 
Measurement of conidial viability. A conidium was considered viable if it grew into a macroscopic colony. The number of colonies that developed from conidia on minimal agar medium with glycerol was expressed as the percentage of colonies that developed from the same number of conidia on minimal agar medium with glucose or sucrose. It was assumed that all conidia on the glucose or sucrose medium developed into visible colonies.

Treatment with mutagen. Conidia were treated with ethyl methanesulphonate (EMS) by the method of Ebner, Mennucci \& Schatz (I973). A I h exposure to $3 \%$ (w/v) EMS killed $80 \%$ of the conidia of T9. Treated conidia were spread on minimal agar medium containing $3 \%(\mathrm{v} / \mathrm{v})$ glycerol and $\mathrm{I} \%(\mathrm{w} / \mathrm{v})$ glucose. After 4 days at $24{ }^{\circ} \mathrm{C}$ the plates were overlaid with $\mathrm{CN}$ medium and returned to $2 \mathrm{r}^{\circ} \mathrm{C}$. Colonies that developed subsequently were tested for auxotrophy (Puhalla \& Mayfield, 1974). Conidia were also irradiated with ultraviolet light using the procedure of Puhalla (1973). Dosage was adjusted for 80 to $90 \% \mathrm{kill}$, and the irradiated conidia were plated as above.

\section{RESULTS AND DISCUSSION}

On minimal medium solidified with $2 \%$ Difco agar, the viability of t9 conidia decreased in the presence of glycerol: on $2 \%$ glycerol, $73 \%$ of the conidia survived at $24{ }^{\circ} \mathrm{C}$; on $4 \%$ glycerol, $58 \%$ survived; and on $8 \%$ glycerol only $22 \%$ survived at the same temperature. The affected conidia germinated and produced short germ tubes but then ceased growing. The germlings became highly vacuolated and sometimes lysed. Similar concentrations of glucose alone did not affect conidial viability.

At higher temperatures, the effect of glycerol on conidial viability was more pronounced. At $19{ }^{\circ} \mathrm{C}$, on minimal agar medium with $3 \%$ glycerol all conidia survived, whereas viability dropped to $66 \%$ at $24{ }^{\circ} \mathrm{C}$ and $0.5 \%$ at $27.5{ }^{\circ} \mathrm{C}$. The same temperatures had no effect on conidial viability when $3 \%$ glucose was substituted for the glycerol.

Other sugars in combination with glycerol greatly increased loss of conidial viability. On minimal agar medium with $3 \%$ glycerol, $66 \%$ of T9 conidia were viable at $24{ }^{\circ} \mathrm{C}$; addition of $\mathrm{I} \%$ glucose, fructose or galactose reduced viability to $0.0 \mathrm{r} \%$. Addition of maltose, cellobiose or sucrose was somewhat less effective, reducing viability to 9,2 and I \% respectively. Czapek-Dox salt solution was as toxic to conidia as the minimal salt solution when in combination with glycerol and $2 \%$ Difco agar.

Increasing the concentration of Difco agar further decreased conidial viability. None of the other brands of agar (BBL, Fisher, or Oxoid) had any effect on viability in combination with glycerol. This difference between Difco agar and BBL agar was not altered by washing them both with acetone or $80 \%(\mathrm{v} / \mathrm{v})$ ethanol. However, in the presence of $3 \%$ glycerol and $1 \%$ glucose, Difco agar treated with charcoal was less toxic (3\% survival) than untreated agar ( $0.01 \%$ survival). Conversely, BBL agar treated with charcoal decreased conidial viability to $4 \%$ in combination with glycerol and glucose. Because the filtered agar suspensions still contained visible traces of charcoal, such changes could result from either the charcoal pretreatment or the residual charcoal in the medium.

On minimal medium containing $3 \%$ glycerol and solidified with silica gel, only $8 \%$ of the conidia produced visible colonies at $24{ }^{\circ} \mathrm{C}$. Addition of I \% glucose to this medium reduced conidial viability to $0.4 \%$.

No glycerol toxicity was observed in liquid cultures or on agar cultures that were inoculated with large pieces of mycelium (mass transfer). Earlier workers (Isaac, 1949; Vega \& Le Tourneau, 1971) used these procedures and thereby failed to discover glycerol toxicity. At $24{ }^{\circ} \mathrm{C}$ T9 conidia were not inhibited by glycerol if, within a day of spreading, they were 
Table I. Effect of overlaying on the viability of conidia of Verticillium dahliae on minimal medium containing $3 \%$ glycerol, I \% glucose and $2 \%$ Difco agar

Media were overlaid with CN medium, as described in Methods. Conidial viability is expressed as a percentage, see Methods. At least 350 conidia were counted in each treatment.

\begin{tabular}{|c|c|c|c|c|c|c|c|}
\hline \multirow[b]{2}{*}{ Strain } & \multirow{2}{*}{$\begin{array}{l}\text { Incubation } \\
\text { temp. } \\
\left({ }^{\circ} \mathrm{C}\right)\end{array}$} & \multicolumn{6}{|c|}{ Conidial viability ( $\%$ ) on medium overlaid after: } \\
\hline & & oh & $24 \mathrm{~h}$ & $36 \mathrm{~h}$ & $48 \mathrm{~h}$ & $72 \mathrm{~h}$ & $96 \mathrm{~h}$ \\
\hline T9 & 19 & 100 & 95 & 92 & 72 & $3 \cdot I$ & NT \\
\hline T9 & 24 & 100 & 85 & $6 \cdot 2$ & 1.8 & 0.1 & NT \\
\hline T9 & 30 & 100 & 45 & $7 \cdot 7$ & $3 \cdot 4$ & I.9 & NT \\
\hline$m e t-I$ & 24 & 100 & 97 & NT & NT & 96 & 92 \\
\hline nic-25 & 24 & 100 & 100 & NT & NT & 91 & 87 \\
\hline nic-I ade-Io & 24 & 100 & 92 & NT & NT & 98 & 91 \\
\hline
\end{tabular}

Table 2. Yields of auxotrophs from conidia of $V$. dahliae T9 treated with mutagens and spread on minimal agar medium containing glycerol

The treated conidia were spread on minimal medium containing $3 \%$ glycerol, $1 \%$ glucose and $2 \%$ Difco agar. CN overlay was applied after 0,4 or 5 days, or not at all. Incubation was at $24{ }^{\circ} \mathrm{C}$. Conidia irradiated with ultraviolet light were incubated in darkness. Numbers in parentheses refer to the number of colonies examined. The viability of surviving conidia refers to the number of colonies that developed on medium that was never overlaid and is expressed as the percentage of colonies that developed from the same number of conidia treated with mutagen, spread on the glycerol medium and overlaid at 0 days. For details of mutagen treatments, see Methods.

\begin{tabular}{|c|c|c|c|c|}
\hline \multirow{3}{*}{$\begin{array}{l}\text { Mutagen } \\
\text { U.v. radiation }\end{array}$} & \multirow{3}{*}{$\begin{array}{l}\text { Viability (\%) on } \\
\text { glycerol medium } \\
\text { of conidia that } \\
\text { survived mutagen } \\
5.4 \\
4.6\end{array}$} & \multicolumn{3}{|c|}{$\begin{array}{c}\text { Percentage of auxotrophs among survivors on } \\
\text { medium overlaid after: }\end{array}$} \\
\hline & & o days & \multirow{2}{*}{$\begin{array}{c}4 \text { days } \\
5.2(300) \\
6.8(132)\end{array}$} & \multirow{2}{*}{$\begin{array}{c}5 \text { days } \\
\text { NT } \\
\text { NT }\end{array}$} \\
\hline & & $\begin{array}{ll}0.9 & (897) \\
0.7 & (715)\end{array}$ & & \\
\hline EMS & $5 \cdot 5$ & $0.5 \quad(1390)$ & $3 \cdot 1(193)$ & NT \\
\hline None & $0 \cdot 1$ & $0.03(6400)$ & NT & $30 \cdot 2(126)$ \\
\hline
\end{tabular}

overlaid with $\mathrm{r} \%$ casein or $0.5 \%$ yeast extract or $\mathrm{CN}$ medium. After one day, however, viability dropped sharply. The onset of inhibition was dependent on temperature (Table I). In contrast about $90 \%$ of the conidia of auxotrophic mutants either alone or mixed with prototrophic conidia could be rescued if overlaying were delayed 4 days (Table I). Microscopic examination revealed that auxotrophic conidia showed no signs of germination on unsupplemented minimal agar medium containing either glycerol or glucose.

Conidia of isolates $\mathrm{V} 44$ and is of $V$. dahliae and of the $V$. albo-atrum isolate were also very sensitive to glycerol. They, too, could be rescued by overlaying with $\mathrm{CN}$.

Conidia treated with EMS or u.v. radiation were spread on minimal agar medium containing glycerol and overlaid with $\mathrm{CN}$ medium after 4 days. Up to ro-fold enrichment for auxotrophs was obtained (Table 2) and there was a broad range of auxotrophs similar to that reported previously (Puhalla \& Mayfield, 1974). On the other hand, there was I000fold enrichment for spontaneous auxotrophs (Table 2) but all required nicotinamide. The poor enrichment among conidia treated with mutagen was attributed to their decreased sensitivity to glycerol (Table 2). 
Enrichment by glycerol should be effective in both $V$. dahliae and $V$. albo-atrum. Use of the medium with other fungi has not been explored.

I wish to cite the excellent and cheerful technical assistance of Linda Hall and Ann Collier.

\section{REFERENCES}

EBNer, E., MenNuCCI, L. \& Schatz, G. (1973). Mitochondrial assembly in respiration-deficient mutants of Saccharomyces cerevisiae. I. Effect of nuclear mutations on mitochondrial protein synthesis. Journal of Biological Chemistry 248, 5360-5368.

Funk, H. B. \& Krulwich, T. A. (1964). Preparation of clear silica gels that can be streaked. Journal of Bacteriology 88, $1200-1201$.

Heale, J. B. (1966). Heterokaryon synthesis and morphogenesis in Verticillium. Journal of General Microbiology 45, 419-427.

ISAAC, I. (1949). A comparative study of pathogenic isolates of Verticillium. Transactions of the British Mycological Society 32, $137-157$.

Puhalla, J. E. (1973). Differences in sensitivity of Verticillium species to ultraviolet irradiation. Phytopathology 63, 1488-1492.

Puhalla, J. E. \& Mayfield, J. E. (1974). The mechanism of heterokaryotic growth in Verticillium dahliae. Genetics 76, 41 I-422.

Vega, R. R. \& Le Tourneau, D. (I97I). Trehalose and polyols as carbon sources for Verticillium spp. Phytopathology 6r, 339-340. 